\title{
Response Inhibition, Categorization, and Set-Shifting in College Students with ADHD Symptoms
}

\author{
Anne M. Murtagh1, Anthony Elworthy² \\ ${ }^{1}$ Shepherd University, Shepherdstown, USA \\ ${ }^{2}$ Wake Forest University School of Medicine, Winston-Salem, USA \\ Email: amurtagh@shepherd.edu
}

Received 4 March 2014; revised 1 April 2014; accepted 29 April 2014

Copyright (C) 2014 by authors and Scientific Research Publishing Inc.

This work is licensed under the Creative Commons Attribution International License (CC BY). http://creativecommons.org/licenses/by/4.0/

(c) (i) Open Access

\begin{abstract}
Attention-deficit/hyperactivity disorder (ADHD) in college students is not well researched nor well understood, but is likely to present special challenges to academic performance. Individuals with ADHD symptoms have sometimes been found to show deficits in executive functioning, including response inhibition, categorization and set-shifting abilities. However, the relationship between these abilities and ADHD symptoms in college students remains unclear. In the present study, the response inhibition, categorization and set-shifting abilities of college students with low $(n=15)$, moderate $(n=15)$, and high $(n=16)$ self-reported ADHD symptoms were compared. No overall group differences were found. It thus appears that in these important executive functions, college students with high self-reported levels of ADHD symptoms are not more impaired, as compared to those with fewer symptoms. Possibly, the group comparisons obscured a subset of students whose cognitive inhibition, categorization and set-shifting abilities are affected. Other limitations, including the use of self-report and the relatively low sample size, are discussed.
\end{abstract}

\section{Keywords}

Attention-Deficit/Hyperactivity Disorder, ADHD, Executive Functions, Cognitive Inhibition, Cognitive Flexibility

\section{Literature Review}

The prevalence and nature of attention-deficit/hyperactivity disorder (ADHD) symptoms in college students is not well studied nor clearly understood (Weyandt \& DuPaul, 2006). Some researchers have estimated that $1 \%$ to $4 \%$ of college students are affected by ADHD (Glutting, Youngstrom, \& Watkins, 2005). College students with 
ADHD are likely to experience a range of difficulties that interfere with social, academic, and occupational functioning. Inattention symptoms in adults take the form of poor time management, problems with concentration, difficulty sustaining attention and completing tasks, and disorganization and forgetfulness (Goodman, 2009). Hyperactive-impulsive symptoms in adults can include restlessness, lack of focus, impulsivity, and poor frustration tolerance (Goodman, 2009). These symptoms would certainly interfere with students' efforts to manage the intellectual and self-regulatory challenges of college. In a study by Rabiner, Anastopoulos, Costello, Hoyle, \& Swartzwelder (2008), first-semester freshmen diagnosed with ADHD reported more academic concerns and depressive symptoms than their non-ADHD peers. A four-year longitudinal study revealed that selfreported ADHD symptoms were associated with persistent misuse of prescription stimulants, even after controlling for other illicit drug use (Arria, Garnier-Dykstra, Caldeira, Vincent, O’Grady, \& Wish, 2011). It is crucial to better understand the symptoms that characterize and accompany ADHD in order to support these students and reduce the risk of the various negative outcomes often associated with ADHD (poor academic achievement, unemployment, underemployment, substance abuse, arrests and convictions; Goodman, 2009).

The role of executive functioning (EF) in ADHD has been the subject of much research in recent years. A number of literature reviews have reported that EF deficits are generally found in children with ADHD, particularly the hyperactive-impulsive type (e.g., Barkley, 1999). On the other hand, based on their 2004 meta-analysis, Hervey, Epstein and Curry observed that while a number of neuropsychological deficits, including EF difficulties, are often found to be associated with ADHD in children, the findings are not consistent (possibly due to methodological and measurement issues).

EF abilities generally improve with age (and presumably brain maturation). ADHD in adults has received much research attention in recent years (e.g., see meta-analyses by Hervey et al., 2004; Willcutt, Doyle, Nigg, Faraone, \& Pennington, 2005), and an exhaustive review is beyond the scope of this paper. However, there are many unanswered questions regarding the association of EF with adult ADHD symptoms. Rapport, Van Voorhis, Tzelepis and Friedman (2001) reported that adults with ADHD generally show impairment in sustained attention tasks and in response inhibition (e.g., on the Stroop Color-Word task), but that findings have been inconsistent for some EF measures. Rapport et al. (2001) compared the performance of adults diagnosed with ADHD to that of a non-ADHD group on a large set of neuropsychological and cognitive measures, including the Stroop and the Wisconsin Card Sorting Test (WCST). They concluded that the difficulties in adults with ADHD may be mild and may affect only specific functions, including response inhibition (Stroop CW and Interference scores), categorization, and cognitive flexibility or set-shifting (WCST errors).

According to a meta-analysis by Hervey et al. (2004), inhibition of motor responses, working memory, and attention were the components of EF most closely linked with ADHD in adults. Hervey et al. report a number of measures and methods that have helped to illuminate the cognitive deficits of adults with ADHD, including the Stroop Color-Word task, measures of verbal fluency, complex motor tasks (especially with set-shifting, as in the WCST, and planning), and measures of working and short-term memory (especially verbal memory). Other authors have also concluded that the Stroop and the WCST are particularly effective in discriminating ADHD from non-ADHD groups among children (Rapport et al., 2001), among adolescents (Reeve \& Schandler, 2001) and among a mixed sample of children, adolescents, and young adults (Seidman, Biederman, Faraone, Weber, \& Ouellette, 1997).

\section{The Present Study}

The present study was designed to assess specific EF abilities, i.e., response inhibition, categorization, and set-shifting, in college students with and without ADHD symptoms. For the purposes of the present study, the level of self-reported ADHD symptoms was considered more relevant than actual ADHD diagnosis for two reasons. First, many individuals with ADHD symptoms may go undiagnosed (Garnier-Dykstra et al., 2010), and, second, some who were diagnosed as children may no longer show symptoms. Thus, we used a well-validated self-report measure of ADHD symptoms (Brown ADD Scales; Brown, 1996), rather than a history of ADHD diagnosis, in an attempt to assess current difficulties with ADHD. We also specifically recruited individuals with a wide range of self-reported ADHD symptoms, and divided this sample into those with low, moderate, or high symptoms. It was predicted that individuals with high levels of ADHD symptoms would show significantly more deficits in response inhibition (Stroop CW and Interference scores), and in both categorization and set-shifting abilities (both assessed by the percent of perseverative responses, percent of perseverative errors, 
and number of completed categories on the WCST) compared to those with low levels of ADHD symptoms.

\section{Methods}

\subsection{Participants}

Undergraduate students from multiple psychology classes at a state college in the northeastern United States were screened using the World Health Organization Adult ADHD Self-Report Scale (ASRS; Kessler et al., 2005), and individuals who reported high levels of ADHD symptoms (12 and above) were specifically invited (through e-mail) to participate in return for research or class participation credit. This was done to ensure that the sample would include a number of individuals with high levels of ADHD symptoms. Participants also included introductory psychology students who volunteered for the study and received research participation credit. Forty-nine students participated in all, but three participants were excluded from the final sample because data were incomplete. This left a sample of forty-six undergraduate students (18 - 50 yrs.; 32 females and 14 males). Participants were primarily Caucasian, with minority groups represented in small numbers. All participants were treated in accordance with APA ethical standards and guidelines.

\subsection{Instruments}

The World Health Organization Adult ADHD Self-Report Scale (ASRS; Kessler et al., 2005). The ASRS is a 6-question screening instrument. These 6 items were selected from a larger set of questions based on results of stepwise regression, to provide the closest match to more formal clinical diagnosis. Kessler et al. (2005) found the ASRS to be reasonably good in sensitivity (68.7\%), in specificity (99.5\%), and in total classification accuracy (97.9\%).

The Brown ADD Scales (Brown, 1996; self-report form). This 40-item self-report measure assesses five symptom clusters related to ADHD: attention, effort, memory, affect, and activation. Likert-style items ask about the frequency of each symptom. The Total Score indicates overall symptom severity (higher scores reflect greater number and/or severity of symptoms). Brown (1996) reports studies showing good reliability and validity for this measure.

The Stroop Color and Word Test (Golden, 1978) was used to assess response inhibition. The Stroop consists of three pages, one with color names printed in black ink, a second page with X's printed in red, green, or blue, and a third page with color names printed in incongruent colors (e.g., RED printed in blue). The respondent is asked to read the words (page 1) or name the colors (pages 2 and 3) as quickly as possible. Most reading adults are inclined to read the stimulus on page 3 (e.g., the word "BLUE" printed in green), but the instructions are to name the color of the ink. Thus, the participant is required to inhibit the automatic response (reading) and focus on the color instead. The Stroop task produces several scores, including Color-Word (CW) score (page 3) and an Interference score (degree of difficulty the individual had with page 3, compared with other pages).

The Wisconsin Card Sorting Test (WCST; Heaton, 1981) was used to assess set shifting (cognitive flexibility) and categorization. The WCST has been shown to reflect verbal abstract and verbal reasoning skills (Golden, Kushner, Lee, \& McMorrow, 1998). The WCST was administered in the standard manner using the two decks of 64 cards, four stimulus cards, and scoring form. In this test, respondents are asked to sort cards by categories, with feedback given after each response; however, the test administrator periodically shifts the criterion for a correct response without telling the respondent. Scores calculated were: perseverative responses and errors, failure to maintain set, number of categories, and learning to learn.

\subsection{Procedure}

Participants were seen in individual sessions of about one hour. They first completed a brief questionnaire that asked gender, age, and whether the individual was color-blind (since the Stroop requires color discrimination, those who reported being color-blind did not participate further). They next completed a self-report version of the Brown ADD Scales. The Stroop and the WCST were then administered, in that order, to the participants. Participants were debriefed at the end of each session.

\section{Results}

Based on Brown ADD Scales total score, participants were split into three groups, a low-symptom group (lowest 
third, scores of 7 - 30; $n=15$ ), a moderate-symptom group (middle third, scores of $31-46 ; n=15$ ), and a high-symptom group (highest third, scores of $48-78 ; n=16$ ). Scores of the high-symptom group fell within the range said to indicate that ADD is probable or highly probable on the Brown ADD Scales (Brown, 1996). However, it should be noted that only three of the participants reported having been diagnosed with ADHD; they were all in the high-symptom group.

It was hypothesized that individuals in the high-symptom group would have significantly poorer performance than those in the low-symptom group on the Stroop Color-Word and Interference scores and on the WCST (percent of perseverative responses, percent of perseverative errors, and number of completed categories). A multivariate ANOVA was used to compare the mean Stroop and WCST scores of all three groups; an alpha of .05 was considered acceptable. There were no significant differences between the three groups in mean Stroop Color-Word or Interference scores or in mean WCST perseverative responses, perseverative errors, or number of completed categories (Wilks' Lambda $F(10,78)=1.058, p=.404$; see Table 1 for means and standard deviations).

\section{Discussion}

The hypothesis that groups high vs. low in ADHD symptoms would differ significantly in their performance on measures of response inhibition, set-shifting, and categorization was not supported. It appears that, for these college students, self-reported ADHD symptoms were not linked to performance in the inhibition of impulses or other automatic responses, conceptual thinking (categorization), or cognitive flexibility (set-shifting).

It is somewhat incongruent that students reporting significant ADHD-type difficulties did not have more difficulty with these tasks. As reported above, a number of studies have shown that adults who are diagnosed with ADHD performed more poorly than the comparison groups in response inhibition, categorization, and set-shifting tasks. For example, the Stroop and the WCST have been shown to be effective in discriminating ADHD from non-ADHD groups among children (Rapport et al., 2001), adolescents (Reeve \& Schandler, 2001) and young adults (Seidman et al., 1997). However, Seidman, Biederman, Weber, Hatch and Faraone (1998) found that self-referred adults diagnosed with ADHD were not impaired in these abilities (nor in a few other EF components), although they performed significantly worse in some EF tasks (e.g., auditory sustained attention). Other research has suggested that neuropsychological measures (including the Stroop and the Conners Continuous Performance Test) were not effective in detecting cognitive impairment symptoms of ADHD in a college population (Sollman, Ranseen, \& Berry, 2010).

It should be noted that in the present study, only a few of the participants in the high-symptom group had actually been diagnosed with ADHD. As explained above, for the purposes of the present study, the level of self-reported ADHD symptoms was considered more relevant than actual ADHD diagnosis for two reasons: 1) the observation that many individuals with ADHD symptoms may go undiagnosed (Garnier-Dykstra et al., 2010), and 2) some who were diagnosed as children may no longer show symptoms. We thus used a well-validated self-report measure of ADHD symptoms (Brown ADD Scales; Brown, 1996), rather than ADHD diagnosis, in an attempt to assess current ADHD-type difficulties. We also specifically recruited individuals with high levels of self-reported ADHD symptoms, to ensure that our participants represented a wide range of symptom levels.

Table 1. Response inhibition, categorization, and set-shifting of groups low $(\mathrm{N}=15)$, moderate $(\mathrm{N}=15)$ and high $(\mathrm{N}=16)$ in ADHD symptoms: Means and standard deviations for Stroop and WCST variables

\begin{tabular}{|c|c|c|c|c|c|c|}
\hline & \multicolumn{3}{|c|}{ M } & \multicolumn{3}{|c|}{ SD } \\
\hline & $\begin{array}{c}\text { Low } \\
\text { symptoms }\end{array}$ & $\begin{array}{c}\text { Mod. } \\
\text { symptoms }\end{array}$ & $\begin{array}{c}\text { High } \\
\text { symptoms }\end{array}$ & $\begin{array}{c}\text { Low } \\
\text { symptoms }\end{array}$ & $\begin{array}{c}\text { Mod. } \\
\text { symptoms }\end{array}$ & $\begin{array}{c}\text { High } \\
\text { symptoms }\end{array}$ \\
\hline \multicolumn{7}{|l|}{ Cognitive inhibition: } \\
\hline Stroop Color-Word & 50.53 & 47.53 & 44.81 & 10.5 & 10.6 & 8.2 \\
\hline Stroop Interference & 3.67 & 3.27 & 1.12 & 7.27 & 9.38 & 7.60 \\
\hline \multicolumn{7}{|c|}{ Categorization and set-shifting: WCST } \\
\hline persev. responses & 12.20 & 12.27 & 15.31 & 8.65 & 7.94 & 13.36 \\
\hline persev. errors & 11.47 & 11.27 & 13.81 & 7.39 & 6.72 & 10.63 \\
\hline no. categories & 5.67 & 5.87 & 5.13 & 1.29 & .52 & 1.75 \\
\hline
\end{tabular}




\section{Conclusions}

For these college students who reported high levels of ADHD-type difficulties, then, those difficulties do not appear to affect the core cognitive and executive functions of cognitive inhibition, conceptual thinking (categorization), or cognitive flexibility (set-shifting). This is fortunate, since these abilities are certainly important to academic and occupational success. However, the fact remains that some college students perceive serious difficulties related to ADHD symptoms. Clearly, further research is needed to clarify the nature of ADHD-type symptoms as they affect these college students, and their relationship to broader cognitive and executive functions.

Limitations of the present study include a relatively small sample size and a predominance of female participants (32 females and 14 males). In studies that compare EF of males and females with ADHD, they tend to show similar patterns in many areas (e.g., Rucklidge, 2006; Seidman et al., 2005). One exception is that males sometimes show more impaired response inhibition (Rucklidge, 2006). Given this finding, it might be expected that Stroop scores of a predominantly female sample might show less of a deficit, compared to a gender-balanced sample; if true, this might help to explain the findings in the present study. However, in this study there were no significant differences between scores of males and females in Stroop CW [males: $M=49.85, S D$ = 9.77; females: $M=47.54, S D=10.22 ; t(39)=-.683, p=.499$ ] or Stroop Interference [males: $M=5.92, S D=$ 6.07; females: $M=1.59, S D=8.81 ; t(38)=-1.591, p=.12]$.

The results of the present study provide further support for the idea that the relationship between ADHD symptoms and EF is a complex one. Since deficits in response inhibition, categorization, and set-shifting difficulties are not universally found in individuals with symptoms of ADHD, or even with diagnosed ADHD, perhaps they are associated only with certain aspects of the disorder. Some researchers have suggested that EF difficulties in general are associated with the inattentive type of ADHD, and not with the hyperactive-impulsive type (Nigg et al., 2005). Biederman et al. (2004) found that only about one-third of their large sample of children and adolescents diagnosed with ADHD showed deficits in EF, but clinical features (e.g., type of ADHD) did not differentiate groups with and without these deficits.

Perhaps, rather than being central to ADHD, EF difficulties might be viewed as a separate condition that is often comorbid with ADHD (Biederman et al., 2006), and that, when present, predict some important negative outcomes. For example, Biederman et al. (2006) provided evidence that EF difficulties in adults with ADHD were significant risk factors for academic and vocational under-achievement, as compared to other adults with ADHD but without EF impairment. Some research has begun to specifically link components of EF to academic skills. For example, Semrud-Clikeman and Harder (2011) found that behavioral inhibition was a useful predictor of written expression skills in college students. It is clear that further research is needed to clarify the cognitive and EF difficulties that might accompany ADHD symptoms in adults, and that there may be important clinical and educational implications of this research. In college settings, more clearly identifying the challenges posed by ADHD and/or EF deficits may significantly reduce the risk of the negative outcomes often associated with ADHD (unemployment, underemployment, substance abuse, arrests and convictions; Goodman, 2009) and improve students' academic and psychological adjustment, as well as later occupational achievement and wellbeing.

\section{References}

Arria, A. M., Garnier-Dykstra, L. M., Caldeira, K. M., Vincent, K. B., O’Grady, K. E., \& Wish, E. D. (2011). Persistent Nonmedical Use of Prescription Stimulants among College Students: Possible Association with ADHD Symptoms. Journal of Attention Disorders, 15, 347-356. http://dx.doi.org/10.1177/1087054710367621

Barkley, R. A. (1999). Response Inhibition in Attention-Deficit Hyperactivity Disorder. Mental Retardation and Developmental Disabilities Research Reviews, 5, 177-184. http://dx.doi.org/10.1002/(SICI)1098-2779(1999)5:3<177::AID-MRDD3>3.0.CO;2-G

Biederman, J., Monuteaux, M. C., Doyle, A. E., Seidman, L. J., Wilens, T. E., Ferrero, F., . . \& Faraone, S. V. (2004). Impact of Executive Function Deficits and Attention-Deficit/Hyperactivity Disorder (ADHD) on Academic Outcomes in Children. Journal of Consulting and Clinical Psychology, 72, 757-766. http://dx.doi.org/10.1037/0022-006X.72.5.757

Biederman J., Petty, C., Fried, R., Fontanella, J., Doyle, A. E., Seidman, L. J., \& Faraone, S. V. (2006). Impact of Psychometrically Defined Deficits of Executive Functioning in Adults with Attention Deficit Hyperactivity Disorder. The American Journal of Psychiatry, 163, 1730-1738. http://dx.doi.org/10.1176/appi.ajp.163.10.1730 
Brown, T. (1996). Brown Attention-Deficit Disorder Scales. San Antonio, TX: The Psychological Corporation.

Garnier-Dykstra, L. M., Pinchevsky, G. M., Caldeira, K. M., Vincent, K. B., \& Arria, A. M. (2010). Self-Reported Adult Attention-Deficit/Hyperactivity Disorder Symptoms among College Students. Journal of American College Health, 59, 133136. http://dx.doi.org/10.1080/07448481.2010.483718

Glutting, J. J., Youngstrom, E. A., \& Watkins, M. W. (2005). ADHD and College Students: Exploratory and Confirmatory Factor Structures with Student and Parent Data. Psychological Assessment, 17, 44-55.

http://dx.doi.org/10.1037/1040-3590.17.1.44

Golden, C. J. (1978). Stroop Color and Word Test: A Manual for Clinical and Experimental Uses. Wood Dale, Illinois: Stoelting Company.

Golden, C. J., Kushner, T., Lee, B., \& McMorrow, M. (1998). Searching for the Meaning of the Category Test and the Wisconsin Card Sort Test: A Comparative Analysis. International Journal of Neuroscience, 93, 141-150. http://dx.doi.org/10.3109/00207459808986419

Goodman, D. W. (2009). ADHD in Adults: Update for Clinicians on Diagnosis and Assessment. Primary Psychiatry, 16, 38-47.

Heaton, R. K. (1981). Wisconsin Card Sorting Test Manual. Odessa, FL: Psychological Assessment Resources.

Hervey, A. S., Epstein, J. N., \& Curry, J. F. (2004). Neuropsychology of Adults with Attention-Deficit/Hyperactivity Disorder: A Meta-Analytic Review. Neuropsychology, 18, 485-503. http://dx.doi.org/10.1037/0894-4105.18.3.485

Kessler, R. C., Adler, L., Ames, M., Demler, O., Faraone, S., Hiripi, E., . . . \& Walters, E. E. (2005). The World Health Organization Adult ADHD Self-Report Scale (ASRS): A Short Screening Scale for Use in the General Population. Psychological Medicine: A Journal of Research in Psychiatry and the Allied Sciences, 35, 245-256. http://dx.doi.org/10.1017/S0033291704002892

Nigg, J. T., Stavro, G., Ettenhofer, M., Hambrick, D. Z., Miller, T., \& Henderson, J. M. (2005). Executive Functions and ADHD in Adults: Evidence for Selective Effects on ADHD Symptom Domains. Journal of Abnormal Psychology, 114, 706-717. http://dx.doi.org/10.1037/0021-843X.114.3.706

Rabiner, D. L., Anastopoulos, A. D., Costello, J., Hoyle, R. H., \& Swartzwelder, H. S. (2008). Adjustment to College in Students with ADHD. Journal of Attention Disorders, 11, 689-699. http://dx.doi.org/10.1177/1087054707305106

Rapport, L. J., Van Voorhis, A., Tzelepis, A., \& Friedman, S. L. (2001). Executive Functioning in Adult ADHD. Journal of the International Neuropsychological Society, 7, 130.

Reeve, W. V., \& Schandler, S. L. (2001). Frontal Lobe Functioning in Adolescents with Attention Deficit Hyperactivity Disorder. Adolescence, 36, 749-765.

Rucklidge, J. J. (2006). Gender Differences in Neuropsychological Functioning of New Zealand Adolescents with and without Attention Deficit Hyperactivity Disorder. International Journal of Disability, Development and Education, 53, 47-66. http://dx.doi.org/10.1080/10349120600577402

Seidman, L. J., Biederman, J., Faraone, S. V., Weber, W., \& Ouellette, C. (1997). Toward Defining a Neuropsychology of Attention Deficit-Hyperactivity Disorder: Performance of Children and Adolescents from a Large Clinically Referred Sample. Journal of Consulting and Clinical Psychology, 65, 150-160.

http://dx.doi.org/10.1037/0022-006X.65.1.150

Seidman, L. J., Biederman, J., Monuteaux, M. C., Valera, E., Doyle, A. E., \& Faraone, S. V. (2005). Impact of Gender and Age on Executive Functioning: Do Girls and Boys with and without Attention Deficit Hyperactivity Disorder Differ Neuropsychologically in Preteen and Teenage Years? Developmental Neuropsychology, 27, 79-105.

http://dx.doi.org/10.1207/s15326942dn2701_4

Seidman, L. J., Biederman, J., Weber, W., Hatch, M., \& Faraone, S. V. (1998). Neuropsychological Function in Adults with Attention-Deficit Hyperactivity Disorder. Biological Psychiatry, 44, 260-268. http://dx.doi.org/10.1016/S0006-3223(97)00392-2

Semrud-Clikeman, M., \& Harder, L. (2011). Neuropsychological Correlates of Written Expression in College Students with ADHD. Journal of Attention Disorders, 15, 215-223. http://dx.doi.org/10.1177/1087054709359169

Sollman, M. J., Ranseen, J. D., \& Berry, D. T. R. (2010). Detection of Feigned ADHD in College Students. Psychological Assessment, 22, 325-335. http://dx.doi.org/10.1037/a0018857

Weyandt, L. L., \& DuPaul, G. (2006). ADHD in College Students. Journal of Attention Disorders, 10, 9-19. http://dx.doi.org/10.1177/1087054705286061

Willcutt, E. G., Doyle, A. E., Nigg, J. T., Faraone, S. V., \& Pennington, B. F. (2005). Validity of the Executive Function Theory of ADHD: A Meta-Analytic Review. Biological Psychiatry, 57, 1336-1346. http://dx.doi.org/10.1016/j.biopsych.2005.02.006 